\title{
TINGKAT KEPEKAAN MANGROVE INDONESIA TERHADAP TUMPAHAN MINYAK (The Sensitivity Levels of Indonesian Mangrove to Oil Spills)
}

\author{
Muarif ${ }^{1,2^{*}}$, Ario Damar ${ }^{3,4}$, Sigid Hariyadi ${ }^{4}$, Mennofatria Boer ${ }^{4}$ dan Dewayani Soetrisno ${ }^{5}$ \\ ${ }^{1}$ Sekolah Pascasarjana, Institut Pertanian Bogor, Jl. Raya Dramaga Bogor 16680. \\ ${ }^{2}$ Jurusan Perikanan, Fakultas Pertanian, Universitas Djuanda, Jl. Tol Ciawi No 1 Bogor 16720. \\ ${ }^{3}$ Pusat Kajian Sumberdaya Pesisir dan Lautan (PKSPL), Institut Pertanian Bogor, \\ Jl Raya Pajajaran Bogor 16143. \\ ${ }^{4}$ Fakultas Perikanan dan Ilmu Kelautan, Institut Pertanian Bogor, Jl. Raya Dramaga Bogor 16680. \\ ${ }^{5}$ Badan Informasi Geospasial (BIG), J1 Raya Cibinong Bogor 16911.
}

*Penulis korespondensi. Tel: 08129910215. Email: muarif2010@gmail.com.

Diterima: 18 April 2016
Disetujui: 31 Agustus 2016

\begin{abstract}
Abstrak
Kepekaan mangrove merupakan komponen penting dalam menentukan tingkat kepekaan ekosistem mangrove terhadap tumpahan minyak. Mangrove Indonesia dapat dikelompokkan dalam 5 tingkat kepekaan terhadap tumpahan minyak, yaitu tidak peka (Acanthus, Nypa, Inocarpus, Acrostichum), kurang peka (Aegiceras, Excoecaria, Hibiscus, Lumnitzera, Ficus, Scyphiphora, Thespasia, Merope, Osbornea, Pandanus), cukup peka (Bruguiera, Ceriops, Xylocarpus, Heritiera), peka (Rhizophora), dan sangat peka (Avicennia, dan Sonneratia). Penilaian terhadap komunitas mangrove di Indonesia menunjukkan sebagian besar tergolong ke dalam katagori sangat peka dan peka apabila komunitas mangrove tersebut terkena tumpahan minyak.
\end{abstract}

Kata kunci: ekosistem, kepekaan, mangrove, pencemaran, tumpahan minyak.

\begin{abstract}
The sensitivity of mangrove is an important component to determine the sensitivity of mangrove ecosystem to oil spills. The Indonesian mangrove can be grouped into five levels of sensitivity to the oil spill, include not sensitive (Acanthus, Nypa, Inocarpus, and Acrostichum), low sensitive (Aegiceras, Excoecaria, Hibiscus, Lumnitzera, Ficus, Scyphiphora, Thespasia, Merope, Osbornea, and Pandanus), intermediate sensitive (Bruguiera, Ceriops, Xylocarpus, and Heritiera), sensitive (Rhizophora), and very sensitive (Avicennia, and Sonneratia). Assessment of mangrove communities in Indonesia showed mostly belong to the category of very sensitive and sensitive if the mangrove communities injured by the oil spill.
\end{abstract}

Keywords: ecosystem, sensitivity, mangrove, pollution, oilspill.

\section{PENDAHULUAN}

Tumpahan minyak merupakan salah satu ancaman pencemaran yang serius di kawasan pesisir Indonesia. Sejak tahun 1975 sampai tahun 2009 tercatat telah terjadi 25 kali tumpahan minyak (Mauludiyah dan Mukhtasor, 2009; Sucipto, 2012). Mangrove sebagai ekosistem penting yang berada di kawasan pesisir menjadi salah satu ekosistem yang rentan terkena tumpahan minyak. Karakteristik ekosistem mangrove yang berada di daerah intertidal dan dipengaruhi pasang surut membuka peluang minyak yang tumpah di dekat pantai akan masuk ke dalam ekosistem mangrove.

Mangrove merupakan ekosistem yang secara ekologi memiliki kepekaan yang tinggi (Brito dkk, 2009) dan kepekaan sangat tinggi serta kronis terhadap tumpahan minyak (Duke, 2016).
Ekosistem mangrove yang terkena tumpahan minyak akan mengalami kerusakan dan masa pemulihannya membutuhkan waktu yang sangat lama, karena minyak dapat terjebak dalam sedimen lebih dari 4 tahun (Lee dkk., 2013). Penelitian Cavalcanti dkk, (2012) mendapatkan pencemaran minyak di Sungai Iriri Brazil telah menurunkan luasan mangrove menjadi $76 \%$, dan sepuluh tahun setelah peristiwa tumpahan minyak kondisi mangrove belum dapat pulih kembali.

Tingkat kerusakan dan kemampuan pulih mangrove terhadap tumpahan minyak salah satunya ditentukan oleh jenis mangrove (Lewis, 1983; Duke $\mathrm{dkk}$,). Tumbuhan penyusunan mangrove memiliki karakteristik pohon yang berbeda-beda, baik dari ukuran, bentuk akar, batang dan daun. Perbedaan tersebut berhubungan dengan adaptasi yang dilakukan terhadap kondisi habitat yang bersalinitas 
dan bersifat anaerob. Perbedaan karakteristik tersebut diperkirakan akan mempengaruhi tingkat kepekaan yang berbeda dari setiap jenis mangrove terhadap tumpahan minyak.

Kepekaan mangrove terhadap tumpahan minyak menjadi faktor penting untuk memperhitungkan tingkat kepekaan lingkungan ekosistem mangrove terhadap tumpahan minyak. Penelitian Andrade dan Szlafsztein (2012), Schallier dkk (2013), serta Sowmya dan Jayappa (2016) yang berkaitan dengan penetapan indeks kepekaan lingkungan telah menetapkan mangrove sebagai habitat yang sangat peka terhadap tumpahan minyak, akan tetapi belum memasukkan kepekaan jenis mangrove sebagai unsur yang diperhitungkan dalam indeks tersebut. Penelitian Rikardi (2013) mengelaborasi kepekaan berdasarkan urutan zonasi mangrove. Zonasi mangrove berhubungan dengan kemampuan adaptasi jenis mangrove terhadap salinitas bukan terhadap tumpahan minyak, sehingga pendekatan ini kurang tepat. Penelitian yang mengelompokkan kepekaan mangrove terhadap minyak berdasarkan aspek fisiologisnya belum ada, padahal menurut Hoff dkk (2002) kepekaan jenis mangrove terhadap minyak ditentukan oleh aspek fisologis mangrove.

Ada 2 faktor yang harus diperhatikan dalam menentukan kepekaan mangrove terhadap tumpahan minyak, yaitu faktor kepekaan setiap jenis mangrove terhadap minyak dan kepekaaan komunitas mangrove. Penelitian ini mengkaji karakteristik fisiologi mangrove di Indonesia dan responnya terhadap pencemaran minyak, sehingga akan didapatkan tingkat kepekaan setiap jenis mangrove terhadap tumpahan minyak. Karakteristik tumbuhan yang hidup di dalam ekosistem mangrove bersifat campuran dan membentuk komunitas mangrove, sehingga juga dibutuhkan acuan baku untuk menentukan tingkat kepekaan komunitas mangrove tersebut. Hasil penelitian ini diharapkan dapat menjadi acuan bagi penentuan tingkat kepekaan mangrove di Indonesia.

\section{METODE PENELITIAN}

\section{Waktu dan Lokasi}

Pengumpulan data penelitian dilaksanakan pada bulan Januari sampai April 2016. Sumber data penelitian adalah skripsi, tesis, dan disertasi dari berbagai perguruan tinggi (Lampiran 1).

\section{Pengumpulan dan Analisis Data}

Teknik pengumpulan data pada penelitian ini adalah pengumpulan data sekunder. Data jenis-jenis mangrove diperoleh dari berbagai penelitian pada 265 stasiun penelitian yang berada di 63 kabupaten dan 26 provinsi di Indonesia. Data tersebut diperoleh dari hasil-hasil penelitian mangrove di Indonesia, baik berupa skripsi, tesis, disertasi maupun jurnal ilmiah (Lampiran 1).

Penelitian ini merupakan penelitian kualitatif dengan pendekatan deskriptif analitik. Analisis data dilakukan melalui pendekatan studi dari berbagai literatur secara komprehensif tentang dampak pencemaran minyak terhadap berbagai jenis mangrove. Menurut Onwuegbuzie dkk (2012), Studi literatur adalah kajian terhadap dokumen tertulis yang menyajikan kasus pendapat secara logika didasarkan pada pemahaman yang komprehensif dan pengetahuan saat ini. Berbagai karakteristik fisiologi mangrove akan dihubungkan dengan karakteristik dampak pencemaran mi.

\section{HASIL DAN PEMBAHASAN}

\section{Tingkat Kepekaan Jenis Mangrove Terhadap Tumpahan Minyak}

Perumusan indikator kepekaan jenis mangrove didasarkan pada dua pendekatan, yaitu pendekatan efek tumpahan minyak terhadap mangrove dan pendekatan karakteristik mangrove baik morfologi, fisiologi maupun reproduksi. Pendekatan efek tumpahan minyak menggambarkan bagaimana minyak mempengaruhi fisik maupun fisiologi tumbuhan, sehingga menimbulkan gangguan bahkan kematian. Pendekatan karakteristik mangrove menggambarkan karakteristik tumbuhan yang hidup di ekosistem mangrove dengan segala kekhasannya dan proses fisiologi yang khas terkait dengan adaptasi terhadap kondisi lingkungan yang ekstrim seperti salinitas yang tinggi dan substrat yang anaerob.

Tumpahan minyak berdampak negatif pada mangrove melalui dua mekanisme, yaitu efek toksikologi serta efek fisik dan fisiologis (Hoff dkk, 2002). Secara toksikologi minyak memiliki sifat herbisida (Emerson, 1983). Hidrokarbon aromatik yang merupakan komponen utama dari campuran minyak diketahui dapat merusak membran sel di akar dan mengganggu pengendalian garam (Hoff dkk, 2002). Cedera akar juga berhubungan dengan senyawa asam alkanoat, fenol dan asam aromatik yang berpotensi dapat terbentuk ketika minyak mengalami biodegradasi oleh mikroorganisme dalam tanah (Hutchinson dan Hellebust, 1974).

Efek tumpahan minyak secara fisik berupa gangguan terhadap fisik tumbuhan karena terselimuti oleh minyak. Akar dan daun merupakan bagian yang peka apabila terkena minyak (Lewis dan Pryor, 2013). Minyak akan menyelimuti mangrove pada bagian akar, batang, dan daun (Clark, 1986; Hoff dkk, 2002). Pengaruh minyak terhadap sistem perakaran mangrove adalah pada permukaan kulit, akar penyangga, dan pneumatofor 
yang berfungsi dalam pertukaran $\mathrm{CO}_{2}$ dan $\mathrm{O}_{2}$ akan tertutup minyak. Hal tersebut akan menurunkan tingkat oksigen dalam ruang akar 1-2\% dalam waktu 2 hari (Clark, 1986). Minyak menyelimuti lentisel pada akar nafas atau pneumatofor sehingga menghambat pertukaran gas (sesak napas) dan manrove dapat mati lemas, menyebabkan kelaparan, gangguan fisik lain atau gangguan fungsi fisiologis, sehingga mangrove mati. Lapisan minyak juga dapat mengganggu pertukaran garam, pada daun dan akar yang terendam (Hoff dkk, 2002). Mangrove mati apabila pneumatofor tertutup sempurna oleh minyak (Böer, 1993).

Dampak minyak yang melekat pada daun dijelaskan oleh Hoff dkk (2002) berupa gangguan pada pertukaran garam. Hutchinson dan Hellebust (1974) mengamati bahwa Ledium palustre yang memiliki kutikula tipis hilang setelah terkena minyak, dan sebaliknya jenis tumbuhan dengan kutikula tebal dan sedikit stomata cukup toleran. Secara fisiologis minyak akan mempengaruhi proses transpirasi, respirasi, dan fotosintesis. Sejumlah proses fisiologis pada tanaman, seperti transpirasi, (konsisten berkurang karena gangguan fisik), respirasi (berkurang atau bertambah), fotosintesis (konsisten berkurang) akibat terpengaruh oleh kontaminasi minyak (Baker, 1971).

Beberapa jenis tumbuhan memiliki tolernsi terhadap tumpahan minyak. Hasil kajian Emerson (1983) diketahui bahwa tumbuhan rhizomatous, tumbuhan berakar rimpang atau stolon, tumbuhan leguminose, dan gulma mampu toleran terhadap tumpahan minyak. Tanaman dengan cadangan makanan bawah tanah besar dalam sistem akar (rimpang, stolons) lebih cepat pulih pasca tumpahan minyak dibandingkan tanaman kurang cadangan makanannya seperti tanaman semusim. Tanaman leguminosae mampu bertahan pada situs terkontaminasi hidrokarbon karena keunggulan kompetitif yang ditawarkan oleh simbiosis hubungan nitrogen antara spesies polongan dan Rhizobium spp. Gulma memiliki kemampuan yang cukup tinggi untuk tumbuh kembali di lokasi tumpahan minyak. Akar rimpang yang lebih besar memiliki lebih banyak karbon dan anorganik sebagai nutrisi, sehingga mampu untuk bertahan hidup pada pengaruh tumpahan minyak (Michel dan Rutherford, 2014).

\section{Pengelompokkan Kepekaan Jenis Mangrove Terhadap Tumpahan Minyak}

Pada 116 stasiun yang menjadi basis data dalam penelitian ini terdapat 36 jenis mangrove yang tergolong ke dalam 21 genus (Tabel 1). Jenisjenis mangrove tersebut memiliki karakteristik fisiologi yang berbeda. Perbedaan karakteristik fisiologi tersebut dapat menjadi penciri tingkat kepekaan yang berbeda terhadap tumpahan minyak.

Hasil studi literatur menunjukkan tingkat kepekaan jenis mangrove terhadap tumpahan minyak dapat didasarkan pada tiga komponen. Ketiga komponen tersebut adalah jenis akar, keberadaan mekanisme adaptasi mangrove terhadap minyak, dan kemampuan pulih pasca tumpahan minyak. Ketinggian lapisan minyak yang mengenai akar dapat digunakan untuk menduga kepekaan ekologi habitat mangrove (Hanna, 1996). Jenis mangrove yang memiliki akar napas dan berpeluang seluruh lentiselnya tertutup minyak (Avicennia dan Sonneratia) tergolong ke dalam jenis yang sangat peka.

Jenis mangrove yang sebagian lentisel di akarnya berpeluang tertutup minyak (Rhizophora) digolongkan peka terhadap tumpahan minyak. Jenis mangrove yang tidak memiliki akar napas dan sebagian akarnya terkena minyak karena muncul ke

Tabel 1. Tingkat kepekaan jenis mangrove

\begin{tabular}{|c|c|c|}
\hline Tingkat kepekaan & Jenis mangrove & Kriteria kepekaan \\
\hline Tidak peka & $\begin{array}{l}\text { Acanthus, Nypa, } \\
\text { Inocarpus, Acrostichum }\end{array}$ & $\begin{array}{l}\text { Mampu beradaptasi terhadap minyak dan mudah } \\
\text { pulih pasca tumpahan minyak. }\end{array}$ \\
\hline Kurang peka & $\begin{array}{l}\text { Aegiceras, Excoecaria, } \\
\text { Hibiscus, Lumnitzera, } \\
\text { Ficus, Scyphiphora, } \\
\text { Thespasia, Merope, } \\
\text { Osbornea, Pandanus }\end{array}$ & $\begin{array}{l}\text { Tidak memiliki akar napas dan akar berada di } \\
\text { dalam tanah sehingga akar tidak mudah terpapar } \\
\text { minyak }\end{array}$ \\
\hline Cukup peka & $\begin{array}{l}\text { Bruguiera, Ceriops, } \\
\text { Xylocarpus, Heritiera }\end{array}$ & $\begin{array}{l}\text { Tidak memiliki akar napas, berakar lutut, papan, } \\
\text { dan banir, sehingga sebagian akar yang muncul ke } \\
\text { permukaan tanah dapat terpapar minyak }\end{array}$ \\
\hline Peka & Rhizophora & $\begin{array}{l}\text { Berakar tunjang sehingga pada rentang pasut yang } \\
\text { rendah sebagian lentisel diakar dapat tertutup oleh } \\
\text { minyak }\end{array}$ \\
\hline Sangat peka & Avicennia, Sonneratia & $\begin{array}{l}\text { Berakar napas dan pada rentang pasut yang rendah } \\
\text { semua bagian akar dapat tertutup minyak, sehingga } \\
\text { akan sesak napas dan mati }\end{array}$ \\
\hline
\end{tabular}


permukaan digolongkan memiliki kepekaan sedang (cukup peka). Jenis mangrove dengan seluruh akar berada di dalam tanah dan tidak mudah terpapar minyak digolongkan jenis yang kurang peka. Adapun jenis mangrove yang tergolong tidak peka terhadap minyak adalah jenis mangrove yang memiliki mekanisme adaptasi terhadap minyak dan mampu pulih secara cepat pasca tumpahan minyak (Tabel 1). Pengelompokkan tingkat kepekaan jenis mangrove ini sejalan dengan hasil penelitian Duke (2016) yang mendapatkan kepekaan jenis mangrove Avicennia yang lebih tinggi dibanding Rhizophora dan Ceriops.

\section{Pengelompokkan Kepekaan Komunitas Mangrove Terhadap Tumpahan Minyak}

Tumbuhan yang hidup di dalam ekosistem mangrove merupakan campuran dari berbagai jenis atau membentuk komunitas mangrove. Penentuan kepekaan mangrove di dalam ekosistem mangrove harus mempertimbangkan karakteristik komunitas yang terbentuk. Karakteristik komunitas mangrove tercermin dari nilai INP (indeks nilai penting), di mana jenis tumbuhan yang memiliki INP tertinggi mengindikasikan sebagai jenis yang mengendalikan komunitas tersebut. INP dapat menjadi acuan dalam menentukan kepekaan komunitas mangrove.

Pengembangan kriteria setiap tingkat kepekaan komunitas mangrove mengacu pada pendekatan Tyler-Walters dkk (2001) dalam mengelompokkan tingkat kepekaan komunitas. Menurut Tyler-Walters dkk (2001) komunitas digolongkan sangat peka apabila jenis yang dominan dalam komunitas akan mati apabila terkena tumpahan minyak, maka terkait dengan komunitas mangrove digolongkan sangat peka apabila jenis mangrove yang sangat peka (akan mati apabila terkena tumpahan minyak) adalah dominan (INP tertinggi) di dalam ekosistem tersebut. Komunitas yang tidak peka tidak mendapat pengaruh tumpahan minyak, maka hal ini sebanding dengan kondisi ekosistem mangrove yang seluruhnya terdiri atas jenis mangrove yang tidak tidak peka. Klasifikasi tingkat kepekaan komunitas mangrove dan kriterianya digambarkan secara rinci dalam Tabel 2.

\section{Sebaran Tingkat Kepekaan Komunitas Mangrove di Indonesia}

Sebaran mangrove di Indonesia sangat luas, menurut Saputro dkk (2009) mangrove di Indonesia memiliki luas sebesar 3.244.018,460 ha. Fungsi mangrove sebagai habitat penting yang menyediakan berbagai nilai ekologi dan jasa lingkungan serta nilai ekonomi menjadikan potensi mangrove yang luas sangat menguntungkan. Untuk menjaga kerberlanjutan produktivitas sumberdaya alam di kawasan pesisir dan laut, maka keberadaan mangrove yang luas harus dipertahankan dan dijaga dari kerusakan.

Dampak besar yang dapat menimbulkan kerusakan ekosistem mangrove secara signifikan adalah tumpahan minyak. Salah satu antisipasi untuk menjaga ekosistem mangrove dari bahaya tumpahan minyak adalah dengan memetakan tingkat kepekaannya. Mangrove yang memiliki tingkat sangat peka mutlak harus dijaga dari gangguan tumpahan minyak, karena apabila terkena tumpahan minyak akan menimbulkan kerugian yang besar baik secara ekologi maupun ekonomi.

Hasil analisis data jenis mangrove dari 63 kabupaten di Indonesia menunjukkan sebagian besar komunitas mangrove di Indonesia tergolong sangat peka dan peka (Tabel 3), hanya sebagian kecil yang tegolong kurang peka dan tidak peka. Persentase sebaran tingkat kepekaan tersebut adalah sangat peka (47\%), peka (40\%), cukup peka $(8 \%)$, kurang peka (4\%), dan tidak peka (1\%).

Data sebaran tingkat kepekaan komunitas mangrove dapat menjadi masukan dalam perumusan kebijakan pengelolaan pesisir, khususnya dalam pengendalian tumpahan minyak.

Tabel 2. Kriteria kepekaan komunitas mangrove.

\begin{tabular}{ll}
\hline \multicolumn{1}{c}{ Tingkat Kepekaan } & \multicolumn{1}{c}{ Kriteria kepekaan komunitas mangrove } \\
\hline Sangat peka & INP tertinggi dimiliki oleh jenis mangrove yang sangat peka terhadap tumpahan minyak \\
Peka & INP tertinggi dimiliki oleh jenis mangrove yang peka atau INP tertinggi dimiliki oleh \\
& jumlah INP jenis mangrove yang sangat peka dan peka terhadap tumpahan minyak \\
Cukup peka & $\begin{array}{l}\text { INP tertinggi dimiliki oleh jenis mangrove yang cukup peka atau INP tertinggi dimiliki oleh } \\
\text { jumlah INP jenis mangrove yang sangat peka, peka dan cukup peka terhadap tumpahan }\end{array}$ \\
& $\begin{array}{l}\text { minyak } \\
\text { Kurang peka }\end{array}$ \\
& $\begin{array}{l}\text { INP tertinggi dimiliki oleh jenis mangrove yang kurang peka atau jenis mangrove yang } \\
\text { peka dan cukup peka terhadap tumpahan minyak }\end{array}$ \\
& Seluruh anggota komunitas adalah jenis mangrove yang tidak peka \\
\hline
\end{tabular}

Sumber: Modifikasi Tyler-Walters dkk (2001) 
Tabel 3. Sebaran tingkat kepekaan komunitas mangrove di Indonesia.

\begin{tabular}{|c|c|c|c|c|c|c|}
\hline \multirow[t]{2}{*}{ No } & \multirow[t]{2}{*}{ Kabupaten } & \multicolumn{5}{|c|}{ Tingkat kepekaan (jumlah stasiun) } \\
\hline & & Sangat peka & Peka & Cukup peka & Kurang peka & Tidak peka \\
\hline 1 & Aceh Singkil & - & 2 & - & - & - \\
\hline 2 & Aceh Besar & 4 & - & - & 2 & - \\
\hline 3 & Langkat & - & 2 & - & 2 & - \\
\hline 4 & Asahan & - & 2 & 2 & - & - \\
\hline 5 & Deli Serdang & 4 & - & 2 & 1 & \\
\hline 6 & Medan & 5 & - & - & - & \\
\hline 7 & Padang & - & 3 & 1 & - & - \\
\hline 8 & Pasaman Barat & - & 3 & - & - & - \\
\hline 9 & Dumai & 2 & - & 2 & - & - \\
\hline 10 & Banyuasin & 3 & 1 & - & - & - \\
\hline 11 & Lampung Timur & 3 & - & - & - & - \\
\hline 12 & Serang & 5 & 1 & - & - & - \\
\hline 13 & Pandeglang & 1 & 2 & - & - & - \\
\hline 14 & Jakarta Utara & 12 & 1 & - & - & 1 \\
\hline 15 & Kepulauan Seribu & - & 3 & - & - & - \\
\hline 16 & Subang & 4 & 3 & - & - & - \\
\hline 17 & Garut & 4 & - & - & 2 & - \\
\hline 18 & Indramayu & 5 & - & - & - & - \\
\hline 19 & Brebes & 3 & 4 & - & - & - \\
\hline 20 & Kendal & 3 & - & - & - & - \\
\hline 21 & Demak & 3 & - & - & - & - \\
\hline 22 & Jepara & 4 & 20 & - & - & - \\
\hline 23 & Rembang & - & 1 & - & - & - \\
\hline 24 & Cilacap & 9 & 5 & 1 & 3 & - \\
\hline 25 & Pasuruan & 1 & - & - & - & - \\
\hline 26 & Banyuwangi & 1 & 1 & 1 & - & - \\
\hline 27 & Gresik & 2 & - & - & - & - \\
\hline 28 & Surabaya & 4 & - & 2 & - & - \\
\hline 29 & Sampang & 2 & - & - & - & - \\
\hline 30 & Sumenep & 2 & 2 & 1 & - & - \\
\hline 31 & Jembrana & - & 3 & - & - & 1 \\
\hline 32 & Dompu & 1 & 2 & - & - & - \\
\hline 33 & Kupang & 4 & 1 & - & - & - \\
\hline 34 & Batu Ampar & - & 6 & - & - & - \\
\hline 35 & Pontianak & 1 & - & - & - & - \\
\hline 36 & Ketapang & - & 1 & - & - & - \\
\hline 37 & Kubu Raya & - & 1 & - & - & - \\
\hline 38 & Kotabaru & 2 & 5 & - & - & - \\
\hline 39 & Tarakan & 1 & - & - & - & - \\
\hline 40 & Kutai & - & - & - & 1 & - \\
\hline 41 & Donggala & 2 & 2 & 1 & - & - \\
\hline 42 & Pinrang & 3 & - & - & - & - \\
\hline 43 & Takalar & 1 & 2 & - & - & - \\
\hline 44 & Wakatobi & - & - & 3 & - & - \\
\hline 45 & Kendari & 7 & 2 & 1 & - & - \\
\hline 46 & Luwuk Bangai & 1 & - & - & - & - \\
\hline 47 & Polman & 1 & - & - & - & - \\
\hline 48 & Tojo Una-una & - & 2 & 1 & - & - \\
\hline 49 & Minahasa Utara & 1 & 1 & - & - & - \\
\hline 50 & Minahasa Selatan & 1 & - & - & - & - \\
\hline 51 & Bunaken & 3 & 5 & 1 & - & - \\
\hline 52 & Kepulauan Talaud & 1 & 3 & - & - & - \\
\hline 53 & Maluku Tengah & 1 & 1 & - & - & - \\
\hline 54 & Seram Barat & - & 2 & 1 & - & - \\
\hline 55 & Halmahra Barat & 1 & 2 & - & - & - \\
\hline 56 & Halmahera Tengah & 1 & 1 & & & \\
\hline 57 & Bintuni & 1 & - & - & - & - \\
\hline 58 & Kaimana & - & 1 & - & - & - \\
\hline 59 & Teluk Wondama & - & 1 & - & - & - \\
\hline 60 & Manokwari & 1 & 2 & - & - & - \\
\hline 61 & Waropen & - & 1 & - & - & - \\
\hline 62 & Jayapura & - & 3 & - & - & - \\
\hline 63 & Merauke & 4 & 1 & - & - & - \\
\hline
\end{tabular}

Sumber: Skripsi, Tesis, Disertasi dari berbagai perguruan tinggi di Indonesia (Lampiran 1) 
Karaketristik komunitas mangrove di Indonesia yang mayoritas memiliki tingkat sangat peka terhadap pencemaran minyak, mengarahkan kebijakan pengelolaan pesisir untuk semaksimal mungkin mencegah terjadinya pencemaran minyak memasuki kawasan mangrove. Pencegahan ini penting karena apabila pencemaran minyak memasuki mangrove akan mengakibatkan kerusakan fungsi ekologi penting di kawasan pesisir, menyulitkan penanganan tumpahan minyak, dan akan menimbulkan biaya pengendalian tumpahan minyak yang mahal. Menurut Kankara dkk (2016), dalam upaya mencegah dan meminimalkan dampak pencemaran minyak, maka efektivitas teknik pencegahan dan intervensi harus dikuatkan.

\section{KESIMPULAN}

Jenis mangrove berperan penting dalam menentukan kepekaan ekologi mangrove terhadap tumpahan minyak. Tingkatan kepekaan setiap jenis mangrove terhadap tumpahan minyak dapat dikelompokkan berdasarkan karakteristik perakarannya. Mangrove di Indonesia dapat dikelompokkan dalam lima tingkat kepekaan terhadap tumpahan minyak, yaitu tidak peka (Acanthus, Nypa, Inocarpus, Acrostichum), kurang peka (Aegiceras, Excoecaria, Hibiscus, Lumnitzera, Ficus, Scyphiphora, Thespasia, Merope, Osbornea, Pandanus), cukup peka (Bruguiera, Ceriops, Xylocarpus, Heritiera), peka (Rhizophora), dan sangat peka (Avicennia, Sonneratia).

Berdasarkan tingkat kepekaan jenis mangrovenya, sebagian besar komunitas mangrove di Indonesia tergolong sangat peka terhadap tumpahan minyak. Karakteristik komunitas mangrove yang sangat peka dan upaya pencucian minyak di habitat mangrove yang sulit dan mahal, maka kegiatan pengendalian tumpahan minyak di Indonesia harus mengutamakan strategi pencegahan tumpahan minyak memasuki kawasan mangrove.

\section{DAFTAR PUSTAKA}

Andrade, M. dan Szlafsztein, C., 2012. Remote Sensing and Environmental Sensitivity for Oil Spill in the Amazon, Brazil, dalam Remote Sensing Applications. InTech. pp. 309-330. Rijeka.

Baker, J.M., 1971. Seasonal Effects of Oil Pollution on Salt Marsh Vegetation. OIKOS., 22:106110 .

Böer, B., 1993 Anomalous Pneumatophores and Adventitious Roots of Avicennia marina (Forssk.) Vierh. Mangroves Two Years After the 1991 Gulf War Oil Spill in Saudi Arabia. Marine Pollution Bulletin, 27(C):207-211.

Brito, E.M.S., Duran, R., Guyoneaud, R., Goñiurriza, M., Oteyza, T.G., De Crapez, M.A.C., Aleluia, I., dan Wasserman, J.C.A., 2009. A Case Study of in Situ Oil Contamination in a Mangrove Swamp ( Rio De Janeiro, Brazil ). Marine Pollution Bulletin, 58(3):418-423.

Cavalcanti, L., Santos, M., dan Cunha-lignon, M., 2012. Long-term Effects of Oil Pollution in Mangrove Forests (Baixada Santista, Southeast Brazil) Detected Using a GIS-based Multitemporal Analysis of Aerial Photographs. Brazilian Journal of Oceanography, 60(2):159-170.

Clark, R.B. 1986. Marine Pollution. Claredon Press. Oxford.

Duke, N.C., Pinzon, Z.S., dan Prada, M.C., 1997. Large-Scale Damage to Mangrove Forests Following Two Large Oil Spills in Panama. Biotropica, 29(1):2-14.

Duke, N.C., 2016. Oil Spill Impacts on Mangroves: Recommendations for Operational Planning and Action Based on a Global Review. Marine Pollution Bulletin, 109(2):700-715.

Emerson, E., 1983. Oil Effects On Terrestrial Plants And Soils: A Review. Ontario Ministry of the Environment. Ontario.

Gudin, C., dan Syratt, W.S., 1975. Biological Aspects of Land Rehabilitation Following Hydrocarbon Contamination. Environ. Pollut., 8:107-112.

Hanna, R.G.M., 1996. An Approach to Evaluate the Application of the Vulnerability Index for Oil Spills in Tropical Red Sea Environments. Spill Science \& Technology Bulletin, 2(3):171-186.

Hoff, R., Hensel, P., Proffitt, E.C., Delgado, P., Shigenaka, G., dan Yender, R. 2002. Oil Spill in Mangrove, Planning and Response Considerations. NOAA Ocean Service, Office of Response and Restoration. Washington.

Hutchinson, T.C., dan Heliebust, J.A., 1974. Oil Spills and Vegetation at Normal Wells. N.,W.T. Environmental-Social Program. Northern Pipelines Task Force, Ottawa, Information Canada Report 73-43. pp. 129.

Kankara, R.S., Arockiaraj, S., dan Prabhu, K., 2016. Environmental Sensitivity Mapping and Risk Assessment for Oil Spill along the Chennai Coast in India. Marine Pollution Bulletin, 106(1-2): 95-103.

Lee, C.H., Lee, J.H., Sung, C.G., Moon, S.D., Kang, S.K., Lee, J.H., Yim, U.H., Shim, W.J., dan Ha, S.Y., 2013. Monitoring Toxicity of Polycyclic Aromatic Hydrocarbons in Intertidal Sediments for Five Years After the 
Hebei Spirit Oil Spill in Taean, Republic of Korea. Marine Pollution Bulletin, 76(12):241-249.

Lewis, M., dan Pryor, R., 2013. Toxicities of Oils, Dispersants and Dispersed Oils to Algae and Aquatic Plants: Review and Database Value to Resource Sustainability. Environ. Pollut., 180:345-367.

Lewis, R., 1983. Impact of Oil Spills on Mangrove Forests in Tasks Jor Vegetation Science, Vol. 8 ed. by H.J. Teas. Dr W. Junk Publishers, The Hague. pp. 171-183.

Michel, J., dan Rutherford, N., 2014. Impacts, Recovery Rates, and Treatment Options for Spilled Oil in Marshes. Marine Pollution Bulletin. 82(1-2):19-25.

Mitchell, W.W., Loynachan, T.E., dan McKendrick, K.J.D., 1979. Effects of Tillage and Fertilization on Persistence of Crude Oil Contamination in an Alaskan soil. J. Environ. Quaff., 8:525-532.

Mauludiyah, dan Mukhtasor. 2009. Perhitungan Skala Biaya Kerugian Akibat Tumpahan Minyak: Relevansinya untuk Perairan Indonesia. Seminar Nasional Teori dan Aplikasi Teknologi Kelautan, 17 Desember 2009.

Onwuegbuzie, J.A., Leech, N.L., dan Collins, K.M.T., 2012. Qualitative Analysis Techniques for the Review of the Literature. The Qualitative Report 2012 [Internet]. 17(56):1-28.
Rikardi, N., 2013. Analisis Metode Indeks Kepekaan Lingkungan Ekosistem Mangrove terhadap Tumpahan Minyak, Studi Kasus di Wilayah Pesisir Kabupaten Subang. Tesis. Sekolah Pascasarjana Institut Pertanian Bogor. Bogor.

Saputro, G.B., Hartini, S., Sukardjo, S., Susanto, A., dan Ponoman, A. 2009. Peta Mangrove Indonesia. Pusat Survei Sumberdaya Alam Laut Bakosurtanal. Cibinong.

Schallier, R, Van Roy, W., dan Van Cappellen, M., 2013. Technical Sub-report 6: Development of an Environmental and Socioeconomic Sensitivity Methodology. Be Aware, Bonn Agreement Belgium. Belgium.

Sowmya, K., dan Jayappa, K.S., 2016. Environmental Sensitivity Mapping of The Coast of Karnataka, West Coast of India. Ocean and Coastal Management, 121:70-87.

Sucipto, A., 2012. Tumpahan Minyak di Perairan Gresik Diteliti. http://regional.kompas.com/ read/2012/11/01/21532747/Tumpahan.Minyak .di. Perairan Gresik Diteliti. [Internet]. [Diunduh 2013-03-28].

Tyler-Walters, H., Hiscock, K., Leur, D.B., dan Jackson, A., 2001. Identifying and ecosystem sensitivities. Report to Department for Environment, Food and Rural Affairs (Final Report). From the Marine Life Information Network (MarLIN), Marine Biological Association of the United Kingdom, Plymouth. 